\title{
The Lived Experiences of Participating in Physical Activity among Young People with Mental Health Problems. A Recovery-Oriented Perspective
}

Authors' contribution:

A) conception and design of the study

B) acquisition of data

C) analysis and interpretation of data

D) manuscript preparation

E) obtaining funding

\author{
Anna Staal ${ }^{1 \mathrm{~B}, \mathrm{C}, \mathrm{D}}$, Ejgil Jespersen ${ }^{2 \mathrm{~A}, \mathrm{D}, \mathrm{E}}$ \\ ${ }^{1}$ University of Copenhagen, Denmark \\ ${ }^{2}$ University of Southern Denmark, Denmark
}

ABSTRACT

There is a growing understanding that psychiatric treatment is more than psychotherapy and medication, and that people themselves can be active in preventing and handling mental health problems. This brings non-medical solutions into play. Physical activity (in terms of exercise, sport, and fitness) becomes an important contribution in this particular context. The perceived mental and physical benefits of physical activity (both preventative and therapeutic) for people experiencing mental health problems are well documented. Typically, this kind of research focuses narrowly on "size of effect" or "most successful type of intervention" or "exercise versus other treatment." Less research has explored the lived experience of physical activity and the meaning and relevance it has for individuals in their everyday lives. This article suggests that sport and exercise can play a valuable role in and contribute to the recovery process for young people with mental health problems. Results from an evaluation study of a developmental project in Denmark shows how physical activity affects a person's lived experiences, relationships, and pursuits. The findings is discussed in relation to the concept of recovery, especially focusing on exercise as a form of self-care strategy, as an opportunity to create social relationships, and as a way to become part of a meaningful social activity.

KEYWORDS young people, physical activity, mental health problems, lived experiences, recovery

\section{Introduction}

There is a growing understanding that psychiatric treatment is more than psychotherapy and medication, and that people themselves can be active in preventing and handling mental health problems. This brings non-medical solutions into play. Physical activity (in terms of exercise, sport, and fitness) becomes an important contribution in this particular context, although the significance of physical activities is usually not valued in mainstream mental health services (Callaghan, 2004). However, the perceived mental and physical benefits of physical activity (both preventative and therapeutic) for people experiencing mental health problems are well documented (Callaghan, 2004; Carless \& Faulkner, 2003; Ellis, et al., 2007; 
Faulkner, 2005; Saxena, et al., 2005; Stathopolou, et al., 2006). Typically, this kind of research focuses narrowly on "size of effect" or "most successful type of intervention" or "exercise versus other treatment". Less research has explored the lived experience of physical activity and the meaning and relevance it has for individuals in their everyday lives.

From the perspective of recovery, the symptoms or activity limitations are not crucial in themselves. It is more a question of the role they play in a person's life (Deegan, 2005; Jensen, 2006; Davidson \& Roe 2007; Topor et al., 2002). Likewise, it is not enough to look at exercise solely as a way to alleviate symptoms or to optimize functioning, but also to ask questions about how the experience of exercise plays a role in the person's everyday life (Careless \& Douglas 2008).

Therefore, we wanted to focus on how physical activity is experienced by participants in a development project promoting physical activity for persons with mental health problems (Staal 2014).

Although the ways in which physical activity are experienced are varied, complex, and closely related to the meaning the activity holds for the individual, it is remarkable how the participants describe their experiences in almost identical terms despite the fact that the they participated in rather different activities in the project's sport clubs. Experiences revolved around relationships, everyday life, and action opportunities.

\section{Method}

\section{Participants}

The participants in the present study were 11 young adults (two men and nine women) aged between 18 and 30 years who were attending an exercise or sport activity in sport clubs for people with mental health problems. The study was part of an evaluation of a development project devoted to enhance the level and quality of exercise and sport activity among young people with mental health problems. Because the research question focused on experiences and not effects of physical activity, we did not collect any special information of diagnosis and anamnesis, but the participants often referred to their mental health problems during the interview. All participants were selected by the local project coordinators in the development project based upon their interest in sharing their lived experiences. All participants provided informed consent. To protect anonymity, all persons in the present study are referred to by pseudonym.

\section{Procedures}

A phenomenological approach underlies the explorative part of the project in that we tried to gather descriptions of the experiences with physical and sport activities as precisely and complete as possible by encouraging the interviewees to describe their experiences rather than to explain or analyze them (MerleauPonty 1962; Kvale 1997).

The first author conducted the interviews in autumn 2013. Interviews were audio-recorded and transcribed verbatim.

\section{Semi-structured interviews}

In total, four semi-structured group interviews with two or three young adults from each of the four involved project settings were conducted. Each participant participated in only one interview. The interviews lasted from 40 minutes to one hour. Group interviews were chosen for data collection partly owing to the limited time and partly owing to the limited resources in the study. An advantage of this method is the dynamic dialogue where the participants validate each other's comments by providing

"checks and balances on each other which weeds out false or extreme views" (Patton 2002, p. 386 cited in Flick 2009, p. 196).

In keeping with the ethos of phenomenological research, the interview schedule served as a loose frame of reference, and where necessary the interviewer deviated from the schedule to explore issues raised by the participants (Kvale 1997). The interview schedule contained questions that invited the participants to 
talk about their previous and present sport and exercise experiences and ways in which sport or exercise have affected them.

The opening question was, "Could you tell me about how it is to do exercise/sport here [in the particular project setting]? " The rest of the interview primarily took the form of follow-up with improvised prompts and clarification questions to explore in more detail the dimensions in the descriptions introduced by the participants.

In most of the interviews, we hadn't usually finished the introductory round before convivial talk began. Participants almost competed for the opportunity to talk about their positive experiences with exercise. They were eager, leaned over the table, got sparkles in their eyes, smiled, and laughed.

According to the phenomenological ideal about "listening without prejudices", the interviewer did not try to control the manner in which topics were covered. Interviewers let experiences unfold without being interrupted by interview questions and with this the connecting assumptions.

\section{Thematic analysis}

We used a thematic and stepwise approach to analyze the lived experiences of participating in sport and exercise activities. In the first step, the first author engaged in several close readings of the interview transcripts and field notes, in order to become immersed in the data. The second step was analysis of individual interviews for units of meaning related to experiences, followed by analysis across individual interviews. The third step was the process of identifying emerging themes by carefully viewing sentences and sentence clusters followed by content analysis using quotations as the unit of analysis with input from the second author. The last step involved returning to the interview transcripts to verify and supplement key findings. For full details of this thematic analysis process, we refer to Kvale (1997).

\section{Findings: The lived experience of participating in exercise and sport activities}

This section describes four themes that emerged when analyzing the transcribed material. In order to make the participants more prominent to the reader and their voices heard, we frequently use quotes from the interviews (Brinkmann \& Tanggaard 2010).

\section{Meaningful relationships}

One of the most recurrent themes in the descriptions of the young adults' experiences with sport and exercise activities concerns relationships and sense of community. Despite the fact that the four sport clubs and their activities are different in many ways, the positive relations, the openness, and inclusiveness that accompany participation in the activities strongly define the essence of the experience for all the participants. Annie described it this way: "We have such a safe setting, and we know each other. And if a new person shows up, well, then we also know this person. There is just room for all!"

The feeling of knowing a new person who has shown up is connected with participants' descriptions of how they meet other young people their own age in sports settings. These people have been through some of the same things as themselves, and who know what it is like to have mental health problems. They are young people with whom they can identify because they feel they are fighting the same kind of battle. Annie describes it as "a totally different understanding and sympathy for one another".

There is room for having a bad day or being bad at the activities without spoiling the atmosphere. As Sophia puts it,

"It's also because it's okay to participate although you are having a bad day. You have this certainty that despite you are feeling very very bad, it's okay to show up". 
They feel understood without having to explain anything. At the same time they emphasize the importance of a common background with histories of mental health problems not being the focus. They are there to participate in a joined activity, as this dialogue exemplifies:

"James: So it's nice to be in a place where you do something together, where it's not about sitting and talking about problems, but where you just are together, and there is this understanding (...).

Emma: That you have this background history, and that it can be tough, but it's not the pivotal point.

Sophia: Yeah, that's it. You feel safe, but at the same time it's not supposed to be a "weeping club" where we sit in a circle and say "oh I feel so bad", but where it just feels safe to be because it's okay".

Furthermore, the common background makes it possible for the participants to identify and see examples in each other. Although they have other friends who, for instance, are getting an education or have started a family, it means something different to see "someone who has also been completely down" reach these goals.

\section{Bodily relations}

In the sports activity the participants are in relationships to embodied persons. For instance, eye contact is essential to boxing, but eye contact is not necessarily an easy thing if you are having mental health problems. As Jody explains:

"In the beginning I found it [eye contact] very intimidating. I couldn't even look myself in the eyes when I looked in the mirror. I had some problems with that. Therefore, to look other people in the eyes was even a bigger challenge. But the more I participate in the boxing activities the easier the eye contact gets".

Another part of the activities during boxing sessions is to shake hands before and after the training which implicates "That we all feel welcome from the beginning", as Annie says, and "It gets more personal when you have to relate to all these people in the room". To be physically active together also results in close physical contact with the other participants. One of the interview groups of girls explained while laughing:

"Jody: We are sweating very heavily, we're about to die

Rita: Yeah! We are bathed in our own sweat, right? And if it's not our own then it's someone else's.

Annie: And we borrow each other's towels to just (...) (showing how she dries her armpit with an imaginary towel)".

The intimacy in sport activities breaks down social barriers. Rita, for instance, describes how she normally finds it hard to invite people to her home, but after sweating together and shaking sweaty hands with the other girls during training, she doesn't feel it will be a problem to invite them to her home, as she puts it:

"Well, it's not a problem with you (Rita gestures towards the other girls in the interview). I don't care because we have been in so close contact so I don't mind you seeing my fuzz balls, it is okay!". 


\section{Doing something to get better and being good to yourself}

Many of the participants describe experiences of "the body getting rid of some feelings" (Melissa) and negative thoughts while training. Annie describes how:

"All the things you struggle with you really get it moved around in the body and get more energy to put a finger on your problems".

Jody says similarly:

"When returning home after boxing for one and a half hours you find yourself moved in things you have been thinking about for a whole week. You get it rearranged and get a better view on it, that is, you see things from another angle. You get more happy and you can cope with a lot more".

Both describe how training gives them an opportunity to act in relation to their negative feelings and problems, "To use your body instead of thinking all the time", as Emma says. This feeling of actually doing something is very important to Catherine, who says:

"If you don't feel like there is anything to be proud of you can at least say: 'But I've been to the gym. I've been exercising. I do something for myself. I do something to get better','

This experience of being able to do something might affect their everyday habits. Jody, for instance, has "started to go for a walk every day (...). And I really like it because it helps you clear your mind", while Annie explains:

"You find out how good it is to be active and move your body. You feel your body! Before I started to practice sport, I was indifferent to everything including how I felt both physically and mentally. When I started doing sports I became more aware of it, and I also acknowledged that you are supposed to be good to yourself".

The experience of being able to do something to get better and enhance one's health is described by Annie and Rita as the reason why they overcame their habit of overeating. To quote Annie:

"Before it was like "Oh, I'm feeling down so I have to stuff a lot of food in my mouth",

whereas now it's more like,

"I'm allowed to eat this because I'm a healthy person".

Her experience of the food and herself is changing as she has become more active. Food becomes a reward instead of a comfort, a way to be good to yourself as Rita describes it:

"So I ordered this really delicious burger and felt good enjoying eating it. And it was okay

because that week I had actually been boxing twice, right? It was much more enjoyable to eat that burger!".

In addition to ridding themselves of bad feelings, they also experience "more well-being" after a training session. Emma describes how she can have an "off day" "and then go do sports and then it is like a little miracle is happening and you are in a good mood again".

\section{More energy - making everyday life easier}

“After one week without exercise you might say that you run low on your batteries" (Peter).

All the interviews have elaborate descriptions of how experiences from exercise and sports activities have an effect that goes beyond the activity itself. This became apparent by the manner in which the participants spoke about the topic. As mentioned before, they were very eager and cheerful and their bodily language radiated enthusiasm when they talked. Some were very surprised about the impact exercise had on their life. Rita describes it as: 
"thought-provoking how it actually influences your everyday life that you just like to use your body!".

They describe how they get physical and mental energy from training, which make everyday life easier:

"Annie: When I return from boxing I have energy to do the dishes or something like that. This is not how it normally is, but I can do it after the boxing and I am happy and feel well. I almost feel like I can handle the whole world!

Rita: After the first exercise sessions I didn't have energy to take a shower... But now it's more like I can do the laundry while I'm in the shower and after that I can just make some food and...You come home and suddenly you are like a tornado that has cleaned the house and taken the dog for an extra walk.

Catherine: I have a hard time falling at sleep at night, but if I've been exercising I get more naturally tired and calm and get a deeper sleep".

The experiences from the exercise and sports activities also ease participation in social settings, for instance, by giving them something to talk about with friends, family, and each other. Peter described a situation where he had done a very good performance during soccer training:

"That is something you remember when you come home. You tell about it at the dinner table. And, believe me, no one was in doubt about what I had been up to that day!".

Changes in the participants' appearance are recognized by family and friends. Rita calls this a new lifestyle and, furthermore, she says:

"My boyfriend has started to call me his boxing-babe so it's becoming sort of an identity. People can sense how happy you are about it. So they dare to start talking to you about it".

Jody describes how her friends support her in participating in the activities and how:

"They think I have become a more positive person to be around and more happy. Now I don't just sit and look anymore without saying anything. Now I'm more like 'listen to me!' I'm more open and I appreciate that".

Also, Melissa describes how it has been easier to go and see friends after she started training: "I can walk to my friends where they live because I've have more physical energy and because my legs can actually carry me". She also describes how exercising has relieved her symptoms, thus has helped her become more socially involved:

"Because of my Tourette's Syndrome and ADHD I can be very tense and I know that if I exercise that tension will go away and I will get extra energy. I also get less tired which result in less tics which result in less social withdrawal (...) so in that way exercise helps in many, many ways".

Doing exercise in special sport clubs is experienced as being different from attending 'mainstream' gyms or sport clubs because the emphasis is on improving levels of health and well-being, rather than increased fitness as an end in itself, or as Lisa says:

"It is actually to be able to function rather than to be fit or superhot".

They experience exercise and sport as a place of refuge where they can have fun and do not feel pressure to perform in a certain way as they feel they should in other places. The data material contains rich descriptions of how exercise and sport activities are a place to gain energy for performing in other settings such as studies or work. 


\section{Discussion}

In response to the findings presented above, where the themes unfolded largely in the respondents' everyday terms, one can ask what it has to do with mental health problems and recovery. Most of the experiences look like common human experiences without being specific to people with mental health problems. Is it not a common thing to experience exercise as affecting mood, mind, and body? In this discussion, we will situate the findings in relation to the everyday lives of people characterized as having mental health problems by relating the findings to the body of work that has emerged around the concept of recovery.

The concept of recovery has achieved great and growing attention within mental health services in recent years (Tew et al., 2012), a tendency also seen in Denmark, where recovery-oriented rehabilitation is in focus for psychiatric services (Regeringens udvalg om psykiatri, 2013; Eplov et al., 2014). No one single authorized definition of recovery exists, but there is a broad agreement about seeing recovery as an individual process that takes place in social contexts. The concept of recovery developed from within the patients' rights movement is conceptually distinct from the medical definition of remission of symptoms. The former focus on recovery as not necessarily recovery from mental illness but emphasizes rebuilding a worthy life, irrespective of continued symptoms or disabilities (Davidson \& Roe 2007), thereby placing the person in a broader life perspective (Jensen 2006; Topor et al., 2002; Topor et al., 2011).

When prompted with questions pertaining to experiences with sports and exercise activities, the young participants in this study ended up describing the active use of physical activity in their fight for recovery as apparent in the findings. Paramount in all the interviews is the hope for change and excitement about overcoming some of the limitations their mental health problems created previously as well as the subsequent experience of development and progress. Participants describe physical activity as connected with the process of practical change in their everyday life. Our findings help to understand some of the ways sport and exercise affect a person's day-to-day experiences, relationships, and pursuits.

Mundane life activities like cleaning the house, doing the dishes, making food, and taking the dog for a walk were described by the participants as activities that were normally hard to complete, whereas after a training session they experienced the energy necessary for getting these things done. In such ordinary activities, the importance of acknowledging the "value of "little things" and "finding pleasure in managing small tasks others might see as trivial" (Borg \& Davidson 2008, p. 135) is coming to the fore. There is a risk of overlooking such experiences and events if the focus is solely on the effect of exercise.

Patricia Deegan (2005) describes with her notion of 'personal medicine' how people with mental health problems use self-care strategies as part of their recovery process. Although many of the self-care strategies are ordinary activities and may be part of many people's everyday lives, it is of great importance to pay attention to these purposeful activities. As our participants described how they used exercise and sport to alleviate various types of distress such as worry, negative and racing thoughts, sleeplessness, and so forth, doing exercise seems to qualify as a self-care strategy (ibid.). Findings also included experiences of exercise being a way to be good to oneself. In a variety of ways exercise created good feelings, gave both energy and peace, and changed people's images of themselves for the better. Taking care of one's body by exercising is a multifaceted self-care strategy.

Tew et al. (2012) emphasize how relationships are vital to recovery as well as how social inclusion involves both the sense of belonging and the engagement in a meaningful social activity. The themes of both Meaningful relationships and Bodily relations illustrate how participating in sport and exercise activities is characterized by social relations as well as how activities are experienced as meaningful in their own right or as vehicles for other outcomes. Also important to recovery are situations in which the person is seen as someone with abilities and where "concrete experiences of being able to exert influence" is provided (Tew et al., 2012, p. 452). This fits very well with the rich descriptions of how exercise was used as a way to manage and get rid of negative feelings and in that way being able to $d o$ something to get better. 
Participation in social communities is of great importance to mental health (Eplov \& Lauridsen 2008) and the positive influence of "social relationships on the risk of death are comparable with well-established risk factors for mortality such as smoking and alcohol consumption" (Holt-Lunstad, Smith \& Layton 2010, p. 20). Doing sports not only offers a social community but is also experienced by the participants as providing good opportunities for creating social relationships.

A variety of friendships and social relations are described in recovery narratives; for instance, friendships between service users which provide an opportunity to interact without having to explain oneself (Topor et al., 2011) was also central to the descriptions given by our participants. Topor et al. describes this experience "that one is not alone" to be of "great importance to the recovery process" (Topor et al., 2011, p. 91).

Therefore, participation in sport settings for persons with mental health problems might enable development of supportive personal relationships. Without entering the discussion fully, we will point to the debate of whether or not attendance in "special sport settings" could be used as a "springboard" for moving on to "normal sport activities" (Raine, Truman, \& Southerst, 2002) or serve to hold back some by providing a long-term alternative to mainstream social participation (Tew et al., 2012). Findings in the development project (Staal, 2014) point in direction of the former. Furthermore, since doing sports is socially valued and encouraged in the wider population, it can help to integrate people with mental health problem into society.

\section{Limitations and further perspectives}

Interviews with the young adults produced extensive knowledge about how participation in exercise and sport activities is experienced, but with a prevailing positive focus. Due to the participating observation the first author made in several of the special sport clubs, she caught a glimpse of the sometimes tough and conflict-ridden situations that also take place in the activities. The reason why this is not an element of this paper is both a consequence of the group interview method and the purposive selection of participants.

The chosen participants all had a more or less well-established relation to the special sport clubs and could therefore be hypothesized to be satisfied with the offered activities. That this experience is, however, not shared by all who show up for the sports and exercise activities was apparent by the fact that all the projects experienced a great flow of young people who participated in the activities only a time or two and then stopped coming. If resources had permitted the first author to participate in and observe the activities over a long period of time, it might have been possible to meet and talk to the young people who only showed up once. This potential data material could complement the existing material by addressing questions about commitment to and relevance of activities.

Participants were interviewed in groups due to limited resources and the study design, although individual interviews would have been preferred if phenomenological research was to be carried out. Future research might benefit from a more rigorous theoretical frame of reference, which was not possible within the present study project. Linking participants' lived experiences more extensively to existing research would help to generalize the findings. The aim of this paper is therefore not to present definite conclusions, but to help to pose new questions for further research.

\section{Conclusion}

The main aim of this article was to explore the subjective experiences of participating in sports and exercise activities from a first-person perspective including the meaning it has for a person's everyday life. What we have learned from the participants is that physical activities provided them with meaningful relations and that the bodily interactions rooted in the activities helped social relations to come about. Furthermore, physical activity was experienced as a way to discover action opportunities and being good to oneself. In addition, participants experienced having more energy after taking up training, which eased their 
everyday life and social relations outside the activity. The discussions suggest that sport and exercise can play a valuable role in and contribute to the recovery process for young people with mental health problems.

\section{Funding and acknowledgements}

The study was supported by the Danish Workers' Sport Union and the National Association for Mental Health. Much gratitude goes to the local project coordinators and, in particular, to the eleven interview persons for sharing their knowledge and experiences of physical activity participation.

\section{REFERENCES}

Borg, M. \& Davidson, L. (2008). The nature of recovery as lived in everyday experience. Journal of Mental Health, 17(2), 129-140.

Brinkmann, S. \& Tanggaard, L. (2010). Kvalitet i kvalitative studier /Quality in qualitative studies/. In: Brinkmann, S. \& Tanggaard, L. (Eds.) Kvalitative metoder - en grundbog /Qualitative Methods - a textbook/ (pp. 521-532). Copenhagen: Hans Reitzels Forlag

Callaghan, P. (2004). Exercise: a neglected intervention in mental health care? Journal of Psychiatric and Mental Health Nursing, 11, 476-483.

Careless, D. \& Douglas, K. (2008). The Contribution of Exercise and Sport to Mental Health Promotion in Serious Mental Illness: An Interpretive Project. International Journal of Mental Health Promotion, 10(4), 5-12.

Carless, D. \& Faulkner, G. (2003). Physical activity and mental health. In: J. McKenna, \& C. Riddoch, Perspectives on Health and Exercise (pp. 61-82). Houndsmills: Palgrave MacMillan.

Davidson, L. \& Roe, D. (2007). Recovery from versus recovery in serious mental illness: One strategy for lessening confusion plaguing recovery. Journal of Mental Health, 16 (4), 459-470.

Deegan, P. (2005). The importance of personal medicine: A qualitative study of resilience in people with psychiatric disabilities. Scandinavian Journal of Public Health, 33 (Suppl 66), 29-35.

Ellis, N., Crone, D., Davey, R., \& Grogan, S. (2007). Exercise interventions as an adjunct therapy for psychosis: A critical review. British Journal of Clinical Psychology, 46, 95-111.

Eplov, L.F. \& Lauridsen, S. (2008). Fremme af mental sundhed - baggrund, begreb og determinanter /Promoting mental health - background, concept and determinants/. Copenhagen: Sundhedsstyrelsen.

Eplov, L.F., Petersen, K.S., Jespersen, E. \& Christensen, K.S. (2014): Rehabiliteringstilbud til patienter med psykiske sygdomme - en recovery-orienteret tilgang /Rehabilitation options for patients with mental disorders - a recoveryoriented approach/. Ugeskrift for Laeger, 176(10), 936-939.

Faulkner, G. (2005). Exercise as an adjunct treatment for schizophrenia. In: G. Faulkner, \& A. Taylor, (Eds.), Exercise, health and mental health: emerging relationships (pp. 27-45). London: Routledge.

Flick, U. (2009). An introduction to qualitative research. Edition 4, SAGE Publications Ltd.

Holt-Lunstad, J. Smith, T.B. \& Layton, J.B. (2010). Social Relationships and Mortality Risk: A Meta-analytic Review. PLoS Medicine, 7(7), 1-20.

Jensen, P. (2006). En helt anden hjcelp /A different kind of help/. Akademisk Forlag, København.

Kvale, S. (1997). InterViews - En introduktion til det kvalitative forskningsinterview /InterViews - An introduction to the qualitative research interview/.1. udg. 15. oplag. Copenhagen: Hans Reitzels Forlag.

Kvale, S. (1983) The Qualitative Research Interview: A Phenomenological and a Hermeneutical Mode of Understanding. Journal of Phenomenological Psychology, 14(2), 171-196.

Merleau-Ponty, M. (1962). The Pheonomenology of Perception. London: Routledge; Atlantic Highlands, NJ: The Humanities Press.

Raine, P., Truman, C. and Southerst, A. (2002). The development of a community gym for people with mental health problems: Influences on psychological accessibility. Journal of Mental Health, 11(1), 43-53.

Regeringens udvalg om psykiatri (2013). En moderne, åben og inkluderende indsats for mennesker med psykiske lidelser /A contemporary, open and inclusive effort for people with mental health illness/. Copenhagen: Ministeriet for Sundhed og Forebyggelse.

Saxena, S., Van Ommeren, M., Tang, K., \&Armstrong, T. (2005). Mental health benefits of physical activity. Journal of Mental Health, 14(5), 445-451.

Staal, A. (2014). Unge, Idrcet og Recovery /Young people, Physical activity, and Recovery/. Odense: Center for Handicap og Bevægelsesfremme, Syddansk Universitet. 
Stathopolou, G., Powers, M., Berry, A., Smits, J., \& Otto, M. (2006). Exercise interventions for mental health: A quantitative and qualitative review. Clinical Psychology - Science and Practice, 13(2), 179-193.

Topor, A., Svensson, J., Bjerke, C., Borg, M. \& Kufås, E. (2002). Vendepunkter - Et ncerstudie af vendepunkter for mennesker der er kommet sig efter alvorlig psykisk lidelse /Turning-points - a study of turning-points for people recovered from severe mental illness/. Copenhagen: Videnscenter for socialpsykiatri.

Topor, A., Borg, M., Di Girolamo, S. \& Davidson, L. (2011). Not Just an Individual Journey: Social Aspects of Recovery. International Journal of Social Psychiatry, 57(1), 90-99

Tew, J., Ramon, S., Slade, M., Bird, V., Melton, J. \& Le Boutillier, C. (2012). Social Factors and Recovery from Mental Health Difficulties: A review of the evidence. British Journal of Social Work, 42, 443-460.

AUTHOR'S ADDRESS:

Ejgil Jespersen

University of Southern Denmark

Institute of Sports Science and Clinical Biomechanics

Campusvej 55

DK-5230 Odense M ,Denmark

Email: ejjespersen@health.sdu.dk 